\title{
Explore the Intention of Clients in Long-Term-Care Facilities to Accept Occupational Therapy Services
}

\author{
Kuo-Chung Huang \\ Professor \\ Department of Business Administration \\ Nanhua University, Chiayi, Taiwan \\ Yu-Che Yang \\ Ph.D. Student \\ Department of Business Administration \\ Nanhua University, Chiayi, Taiwan
}

\begin{abstract}
This study applies the theory of planned behavior to investigate the intention of clients who lived in the long-termcare facilities and accepted occupational therapy service provided by Hosanna Hospital. The secondary data provided by Hosanna Hospital.Altogether84 valid data in this study. Empirical results reveal that the clients' attitude toward the behavior, subjective norm and perceived behavioral control respectively positive effect on their intention. Perceived behavioral control has the most significant impact on intention. Subjective norm has a partial mediation effect on attitude toward the behavior to the intention and the perceived behavioral control has a complete mediation effect on attitude toward the behavior to the intention. Occupational therapists should help the clients to perceive their need, promote their ability to handle external resources, actively communicate with the people who influence the clients' decision and offer the optimal intervention to rise the clients' intention.
\end{abstract}

Keywords: Occupational Therapy Services, Theory of Planned Behavior, Intention, Mediation Effect.

\section{Introduction}

Taiwan has been facing the aging problem and increasing needs of long-term care. The National Health Insurance has implemented in Taiwan since 1995.The comprehensive health care has elevate the life expectancy of people. The statistical report by Department of Statistics, Ministry of the Interior in Taiwan (2018) show that the average life expectancy of people in Taiwan has risen from 74.53y (1995) to 80y (2016). With the falling of the child birth rate from $15.50 \%$ (1995) to $8.23 \%$ (2017), the proportion of aging population has rose from $7.63 \%$ (1995) to $13.86 \%$ (2017) at the same time. According to the Statistics of internal affairs by Department of Statistics, Ministry of the Interior in Taiwan (2018) pointed out that more than 14 percent of people living in Taiwan were over 65 years old in March 2018. In particular, the proportion of elderly people living in the Chiayi area is $18.61 \%$, the highest aging population in Taiwan. Such a feature shows that the elderly population has increased rapidly. The further estimated report by National Development Council in Taiwan (2018) indicated that the proportion of the elderly people in Taiwan might exceed $20 \%$ in 2026. Although high quality of health care can extend the life expectancy, but the diseases, accidents, heredity, aging or other issues may lead the clients to face their partial loss of physical function, especially for aged society in Taiwan. In this regard, the issue of long-term care plays an important role in such a situation. We need prudently to deal with the subject of supply and demand about long-term care services.

Traditionally in Taiwan, when people cannot success in their activities of daily living, the burdens of taking care of them often fall on their family members. Whether the physiological, psychological or economic, their family always suffer a considerable burden. Besides seeking for help from the public sector to provide the home base reablement services, the long-term care facilities services may be choices when their family cannot provide a safe and suitable environment, or cannot burden the care loading but they can afford the cost of long-term care facilities' services (Groger, 1995). 
According to the statistical report by Social and Family Affairs Administration Ministry of Health and Welfare in Taiwan (2018), the number of long-term care facilities has risen from 1,408 (2008) to 1,644 (2017) and the beds for long-term care has risen from 89,170 (2008) to 115,787 (2017).The figure show that with the increasing of aging population, the facilities base of the long-term care services has risen rapidly either.

The professional occupational therapy services are very important to the clients who live in the long-term care facilities. Occupational therapists make effort to understand which factor influence the client's occupational performance by occupational science, theory and activities analysis, then apply the purposeful therapeutic activities, assist devices, job accommodation, environment renovation, cognitive training, splinting and so on to maintain or improve the clients' physical and mental function and prevent functional degradation. Face the vast number of potential clients come from the long-term care facilities and need to intervene by occupational therapist. The occupational therapists need to think about how to provide the optimal occupational therapy services to the clients.

More scholars indicated that providing friendly, kind and professional heath care service can attract and retain clients and to develop potential clients. Trying to understand and master the clients' intention can improve clients' future purchase decision and recommend the benefits of services to other people in need (Brady \& Cronin, 2001; Kim, Ferrin, \& Rao, 2009; Sedianingsih \& Prasetyo, 2016).

The Theory of Planned Behavior is the famous behavioral psychology theory in social psychology (Ajzen, 1985) and evolved from the Theory of Reasoned Action (Fishbein \& Ajzen, 1975). The theory could be employed to have some knowledge about the behavior of human beings, such as the subject regard to consumer behavior, education, health care and so on. Theory of Planned Behavior provides a theoretical framework to predict an individual's intention to engage in a behavior at a specific time and place. In this study, we obtain the secondary data from the Hosanna hospital and apply the Theory of Planned Behavior to analyze the intention of the clients who live in the long-term care facilities to accept the occupational therapy services. The empirical results allow the occupational therapists to understand what the clients want. Simultaneously, the occupational therapists can provide the optimal occupational therapy services to help the client and apply the services experience to help the more clients in the future.

\section{Literature Review}

\subsection{Occupational Therapy in Long-Term-Care Facilities}

In recent years, there were many research topics about occupational therapy services in long-term-care facilities. Some studies indicated that the professional occupational therapy services plays an important role in enhancing the occupational performance and development of an occupational therapy delivery model, testing and scale for long-term care facilities (Chapparo \& Rankab, 1997; Lo, et al., 2002; Lu, Lien \& Hsieh, 2015). Partial studies point out the occupational therapists apply more expressive touch to the clients, encourage the clients to make choices of everyday tasks by themselves, use the purposeful therapeutic activities and so on to improve the client's occupational performance. Help the clients to adapt their life cycle, living environment and to improve their quality of lives or subjective sense of wellness (Duncan-myers \& Huebner, 2000; Müllersdorf \& Ivarsson, 2012; Sampaio \& Ito, 2013; Ng et al., 2013; Morris, et al., 2014).

\subsection{Theory of Planned Behavior}

The Theory of Planned Behavior indicated that the determinant behavior is one's intention to engage in that behavior and the intention determined by three constructs: Attitudes toward the behavior, Subjective norms, and Perceived behavioral control (Ajzen, 1991). In this study, the construct of "Attitude toward the behavior" was defined as evaluating cognition of the clients about the service's benefit, professionalism, and their feeling of accepting occupational therapy services. "Subjective norm" was defined as examining how the people such as their family, relatives, friends and others influence the clients' decision to accept occupational therapy services. "Perceived behavioral control" was defined as observing how the clients have cognition about their physical dysfunction, dependence in activities of daily living, financial condition and their ability to handle external resources. "Intention" is defined as when the clients has higher intention, he or she would still choose to accept occupational therapy services even they face unpredictable obstacles.

\subsection{Hosanna Hospital}

Hosanna Hospital is one of the National Health Insurance providers (NHI, 2018) in Taiwan and is dedicated to professional services related to chronic diseases. 
To achieve this goal, the hospital provides rehabilitation services, hem dialysis, respiratory care wards and nursing homes in the Chiayi district of Taiwan. The hospital also accepts commissions from some long-term care institutions to provide medical services to its clients. In order to improve service quality, the hospital also conducts post-service questionnaire surveys for customers to help the various departments to improve service.

\section{Methodology}

\subsection{Research Model and Hypotheses}

Figure 1 shows the research model considered.

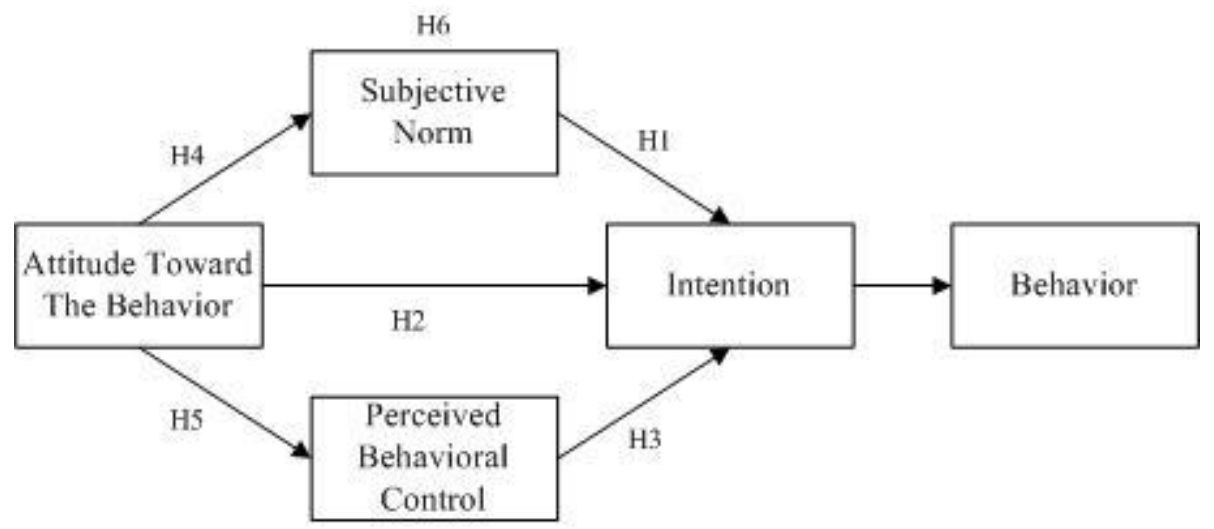

$\mathrm{H} 7$

Figure 1: Research model

According to the research model, seven hypotheses considered arelistedas follows:

H1. Subjective norm of the clients has plays a positive role in affecting the clients' intention to accept occupational therapy services.

H2. Attitude toward the behavior of the clients has plays a positive role in affecting the clients' intention to accept occupational therapy services.

H3. Perceived behavioral control of the clients has plays a positive role in affecting theclients' intentionto accepts occupational therapy services.

H4.Attitude toward the behavior of the clients has plays a positive role in affecting the clients' subjective norm.

H5.Attitude toward the behavior of the clients has plays a positive role in affecting the clients' perceived behavioral control.

H6.Subjective norm of the clients has a mediation effect between clients' attitude toward the behavior and the intention.

H7. Perceived behavioral control of the clients has a mediation effect between clients' attitude toward the behavior and the intention.

\subsection{Data Collection and Data Analysis}

We got the latest data of the post-service questionnaires and items from the database provided by Hosanna Hospital. We obtained authorization from Hosanna Hospital (Approval No. 47) to use the secondary data. The original post-service questionnaires items were be designed by the chief of each department and apply the fivepoint Likert-type scale to indicate the respondents' agreement or disagreement with the post-service questionnaires items. The level of agreements in the Likert-type scale utilized responses from 1 to 5, where 1: Strongly Disagree; 2: Disagree; 3: neither Agree nor Disagree; 4: Agree; 5: Strongly Agree. Simultaneously, the content of the questionnaire also include the source of the clients, the health care service department of the clients accepted, gender, age, duration, marital status, education degree and so on. In this study, the sample chosen standard were be the clients who living in the long-term care facilities and accepted the occupational therapy services course provided by Hosanna Hospital. Finally, we were collected 84 valid data in this study.

In this study, based on the relevant literature and professional suggestion from three experienced people: director of nurse, an occupational therapy staff and a professional scholar and then classify the items of the post-service questionnaires into four construct. The collected data has content validity. 
In the construct of "Attitude toward the behavior", seven items were be classified based ontwo studies (Ajzen, 1991; Blackwell, Engel \&Miniard, 2001). Inthe construct of "Subjective norm" construct, six items were be classified based on the works done by some scholars (Ajzen, 1991; Kanuk \& Schiffman, 2000). Five items in the construct of "Perceived behavior control" construct were be classified based on two studies (Ajzen, 1991; Taylor \& Todd 1995). Four items in the construct of "Intention" construct were be classified based on the works by some scholars (Ajzen, 1991; Zeithaml, Berry \& Parasuraman, 1996). Additionally, six items including gender, age, duration, marital status,education degree, the important one who decided whether the client will accept occupational therapy services or not, were designed to collect the demographic information. In order to increase the reliability of the collected data in this study, we deleted some items during the process of statistical analysis by following Nunnally's (1978) suggestion. If an item with standardized factor loading lower than 0.5, value of corrected item to total correlation lower than 0.5 and with the value of Cronbach's alpha if item deleted greater than value of Cronbach's alpha, the item should be deleted. Four items were then deleted and the numbers of the resulting items for each construct were six items for "Attitude toward the behavior", five items for "Subjective norm", four items for "Perceived behavior control", three items for "Intention" and six items for collecting the demographic information.

\section{Analysis and Discussion}

\subsection{Demographic Information}

Altogether 84 valid data were collected in this study. 51.19 percent of the respondents were male and $67.86 \%$ were above 65 years old. 63.1 percent of the respondents' duration of staying in long-term-care facilities were below 3 years. $47.62 \%$ of the respondents were married, 17.86 percent were illiterate, and 10.71 percent decided to accept occupational therapy services by themselves. Detailed descriptive statistics related to the respondents' characteristics were shown in Table 1.

Table 1: Sample demographic information

\begin{tabular}{|c|c|c|c|}
\hline Item & Answering Options & Frequency & Percent \\
\hline \multirow[t]{2}{*}{ Gender } & Male & 43 & 51.19 \\
\hline & Female & 41 & 48.81 \\
\hline \multirow[t]{5}{*}{ Age } & $<65$ years & 27 & 32.14 \\
\hline & $65-69$ years & 8 & 9.52 \\
\hline & $70-74$ years & 13 & 15.48 \\
\hline & $75-79$ years & 16 & 19.05 \\
\hline & $\geqq 80$ years & 20 & 23.81 \\
\hline Duration & $<2$ years & 12 & 14.29 \\
\hline (How long have you & 2- 3 years & 41 & 48.81 \\
\hline been in your facilities & 4- 5 years & 7 & 8.33 \\
\hline \multirow[t]{2}{*}{ ?) } & 6- 7 years & 13 & 15.48 \\
\hline & $\geqq 8$ years & 11 & 13.09 \\
\hline \multirow[t]{4}{*}{ Marital status } & Married & 40 & 47.62 \\
\hline & Single & 8 & 9.52 \\
\hline & Widowed & 31 & 36.91 \\
\hline & Divorce & 5 & 5.95 \\
\hline \multirow[t]{6}{*}{ Education } & Illiterate & 15 & 17.86 \\
\hline & Literacy & 14 & 16.67 \\
\hline & Elementary School & 18 & 21.43 \\
\hline & Junior high School & 12 & 14.28 \\
\hline & Senior high School & 15 & 17.86 \\
\hline & Above College (contained) & 10 & 11.90 \\
\hline Who decided & Self & 9 & 10.71 \\
\hline (The important one & Spouse & 20 & 23.81 \\
\hline who decided whether & Son & 31 & 36.91 \\
\hline the clientwill accept & Daughter- In- Law & 6 & 7.14 \\
\hline \multirow{3}{*}{ OT services or not ) } & Daughter & 8 & 9.53 \\
\hline & Parents & 4 & 4.76 \\
\hline & Others & 6 & 7.14 \\
\hline
\end{tabular}




\subsection{Factor Analysis, Reliability Analysis and Means Analysis}

According to Kaiser(1974) suggested, "the Kaiser-Meyer-Olkin (KMO) value is greater than0.7"and "Bartlett's test of sphericity is significant "are the standard to exam the suitability of variable for factor analysis. In this study, KMO value of attitude toward the behavior, subjective norm, perceived behavioral control and intention was $0.888,0.858,0.807$ and 0.726 respectively. Each construct's KMO value is greater than 0.7, and each construct's Bartlett's test of sphericity is significant, implying that it is suitable for factor analysis. The results of factor analysis for each construct were shown in Table 2. For the items of attitude toward the behavior, subjective norm, perceived behavioral control and intention, all the items' factor loadings are greater than 0.5, with the sum of variance explained respectively given by $92.797 \%, 77.011 \%, 85.504 \%, 90.421 \%$. No items should be deleted and one principal factor was extracted from each construct. To examine the reliability, all the values of Cronbach's alpha are greater than 0.7 , implying a high degree of internal consistency.

Table 2: Results of factor analysis and reliability analysis

\begin{tabular}{|c|c|c|c|c|c|}
\hline \multirow[b]{2}{*}{ Construct } & \multirow[b]{2}{*}{ Item } & \multicolumn{3}{|c|}{ Factor Analysis } & \multirow{2}{*}{$\begin{array}{l}\text { Cronbach's } \\
\text { alpha }\end{array}$} \\
\hline & & $\begin{array}{l}\text { Factor } \\
\text { Loading }\end{array}$ & $\begin{array}{l}\text { Eigen } \\
\text { Values }\end{array}$ & $\begin{array}{l}\% \text { of } \\
\text { Varia } \\
\text { nce }\end{array}$ & \\
\hline \multirow{6}{*}{$\begin{array}{l}\text { Attitude } \\
\text { toward the } \\
\text { behavior }\end{array}$} & $\begin{array}{l}\text { Occupational therapists' service attitude is } \\
\text { satisfactory. }\end{array}$ & 0.977 & 5.568 & $92.797 \%$ & 0.984 \\
\hline & $\begin{array}{l}\text { Occupational therapy services can enhance your } \\
\text { occupational performance. }\end{array}$ & 0.971 & & & \\
\hline & $\begin{array}{l}\text { Occupational therapy services can improve your } \\
\text { quality of life. }\end{array}$ & 0.971 & & & \\
\hline & $\begin{array}{l}\text { Occupational therapy services can maintain your } \\
\text { esteem. }\end{array}$ & 0.966 & & & \\
\hline & Occupational therapy services can fit your need. & 0.949 & & & \\
\hline & $\begin{array}{l}\text { Occupational therapists can link with other } \\
\text { professionals for you if you need. }\end{array}$ & 0.947 & & & \\
\hline \multirow[t]{5}{*}{$\begin{array}{l}\text { Subjective } \\
\text { norm }\end{array}$} & $\begin{array}{l}\text { Medical staff's recommendation will affect your } \\
\text { willing to accept the occupational therapy } \\
\text { services. }\end{array}$ & 0.926 & 3.851 & $77.011 \%$ & 0.923 \\
\hline & $\begin{array}{l}\text { Support by relative members will affect your } \\
\text { willing to accept the occupational therapy } \\
\text { services. }\end{array}$ & 0.898 & & & \\
\hline & $\begin{array}{l}\text { Support by friends will affect your willing to } \\
\text { accept the occupational therapy services. }\end{array}$ & 0.859 & & & \\
\hline & $\begin{array}{l}\text { Long-term-care facilities staff's } \\
\text { recommendation will affect your willing to } \\
\text { accept the occupational therapy services. }\end{array}$ & 0.884 & & & \\
\hline & $\begin{array}{l}\text { Support by family members will affect your } \\
\text { willing to accept the occupational therapy } \\
\text { services. }\end{array}$ & 0.816 & & & \\
\hline \multirow{4}{*}{$\begin{array}{l}\text { Perceived } \\
\text { behavioral } \\
\text { control }\end{array}$} & $\begin{array}{l}\text { Accept the occupational therapy services due to } \\
\text { your activities of daily living dependent. }\end{array}$ & 0.952 & 3.420 & $85.504 \%$ & 0.938 \\
\hline & $\begin{array}{l}\text { Accept the occupational therapy services due } \\
\text { your physical dysfunction. }\end{array}$ & 0.933 & & & \\
\hline & $\begin{array}{l}\text { National health insurance can burden the cost of } \\
\text { occupational therapy services. }\end{array}$ & 0.931 & & & \\
\hline & $\begin{array}{l}\text { Your financial condition can burden the cost of } \\
\text { occupational therapy services. }\end{array}$ & 0.881 & & & \\
\hline Intention & Without the free transportation shuttle provide & 0.971 & 2.713 & $90.421 \%$ & 0.944 \\
\hline
\end{tabular}


occupational therapy services.

Without the free transportation shuttle provide by your long-term-care facilities, you would still choose to accept occupational therapy services. You would still choose to accept occupational 0.916 therapy services if you need.

Means analysis was done to determine whether the demographic characteristics were significantly different in statistics for each construct. Independent samples $\mathrm{T}$ test was adapted to gender. For the other demographic items, one-way ANOVA with Scheffe's test of post-hoc comparisons was conducted. It is considered that there are significant statistical differences when $\mathrm{p}<0.05$. Among the six demographic items, level of age was significantly related to attitude toward the behavior, perceived behavioral control and intention of the clients in long-term-care facilities. For attitude toward the behavior and perceived behavioral control, the means of below 65 (contained) years old, 65-69 years old, 70-74 years old were greater than that of 75-79 years old. For behavioral intention, the mean of below 65 (contained) years old was higher than 70-74 years. The results show that younger clients in long-term-care facilities often positively face their disability and actively search for occupational therapy services. The level of marital status was significantly related to four constructs. For attitude toward the behavior, subjective norm and intention, the mean of the married was higher than that of the widowed. For perceived behavioral control, the mean of the married was higher than that of the singled and the widowed. The results infer that clients with marital relationship often positively and actively search for occupational therapy services since they receive more concern and support from his or her family. The degree of education was significantly related to four constructs. The mean of above college (contained) was higher than that of the illiterate. Reasonable explanation is the education level above college (contained) of the clients has higher ability to seek health care resources than illiterate. The important one who decided whether the client will accept occupational therapy services or not is significantly related to attitude toward the behavior, perceived behavioral control and intention of the clients in long-term-care facilities. For attitude toward the behavior, the means of self and spouse were higher than that of daughter in law. For perceived behavioral control, the mean of self was higher than that of daughter-in-law and others, and that of spouse was higher than that of others. For intention, the mean of self was higher than that of daughter-in-law and others, and that the mean of spouse was higher than that of daughter-in-law. The results show that the clients in long-term-care facilities and their spouses are more actively than daughters-in-law and others in searching for occupational therapy services to improve client's disability.

\subsection{Regression Analysis}

Table 3 and Table 4 showed the results of regression analysis. The standardized regression coefficient of the construct of attitude toward the behavior, subjective norm and perceived behavioral control to intention was 0.812, 0.806and0.862respectively. The standardized regression coefficient of the construct of attitude toward the behavior to the subjective norm and perceived behavioral control was respectively given by $0.857,0.905$. All the results were statistically significant and therefore the hypothesis of $\mathrm{H} 1 \sim \mathrm{H} 5$ were not be rejected. As a result, the residents 'attitude toward the behavior, subjective norm and perceived behavioral control positively affected the intention of the clients in long-term care facilities toaccept occupational therapy services. In particular, perceived behavioral control has great affected on clients' intention than the attitude toward the behavior and subjective norm.

Table 3:Mediation effect analysis (mediator: subjective norm)

\begin{tabular}{|c|c|c|c|c|}
\hline Dependent Variable & $\begin{array}{l}\text { Subjective } \\
\text { norm }\end{array}$ & Intention & Intention & Intention \\
\hline \multicolumn{5}{|l|}{ Independent Variable } \\
\hline & Model 1 & Model 2 & Model 3 & Model 4 \\
\hline Attitude toward the behavior & $0.857^{* * *}$ & $0.812^{* * *}$ & & $0.458^{* * *}$ \\
\hline Subjective norm & & & $0.806^{* * *}$ & $0.413^{* *}$ \\
\hline $\mathrm{R}$ & 0.857 & 0.812 & 0.806 & 0.840 \\
\hline $\mathrm{R}^{2}$ & 0.734 & 0.660 & 0.649 & 0.705 \\
\hline $\operatorname{adj} \cdot R^{2}$ & 0.731 & 0.655 & 0.645 & 0.698 \\
\hline F-value & 226.640 & 158.870 & 151.610 & 96.761 \\
\hline
\end{tabular}


Mediation effect of subjective norm was examined with respect to criterion proposed by Baron and Kenny (1986).Compare the results given in model 2 and model 4in Table 3, the standardized regression coefficient of attitude toward the behavior decreased from 0.812 to 0.458 , after adding subjective norm in regression model. Attitude toward the behavior was still significantly positive effect on intention in model 4. As a result, the clients' subjective norm has a partial mediation effect on the relationships between attitude toward the behavior and intention. Hence, the hypothesis of H6 was not rejected.

Table4:Mediation effect analysis (mediator: perceived behavioral control)

\begin{tabular}{|c|c|c|c|c|}
\hline $\begin{array}{l}\text { Dependent Variable } \\
\text { Independent Variable }\end{array}$ & $\begin{array}{l}\text { Perceived } \\
\text { behavioral } \\
\text { control }\end{array}$ & Intention & Intention & Intention \\
\hline & Model 1 & Model 2 & Model 3 & Model 4 \\
\hline Attitude toward the behavior & $0.905^{* * *}$ & $0.812^{* * *}$ & & 0.180 \\
\hline Perceived behavioral control & & & $0.862^{* * *}$ & $0.699^{* * *}$ \\
\hline $\mathrm{R}$ & 0.905 & 0.812 & 0.862 & 0.865 \\
\hline $\mathrm{R}^{2}$ & 0.819 & 0.660 & 0.742 & 0.748 \\
\hline $\operatorname{adj} . R^{2}$ & 0.817 & 0.655 & 0.739 & 0.742 \\
\hline F-value & 370.693 & 158.870 & 236.106 & 120.258 \\
\hline
\end{tabular}

Mediation effect of perceived behavioral control on the relationships between attitude toward the behavior and intention. Compare the results given in model 2 and model 4 in Table 4, the standardized regression coefficient of attitude toward the behavior decreased from 0.812 to 0.180 , after adding perceived behavioral control in regression model. Attitude toward the behavior was not significantly positive effect on intention in model 4 . As a result, the perceived behavioral control has a complete mediation effect on the relationships between attitude toward the behavior and intention. Hence, the hypothesis of $\mathrm{H} 7$ was not rejected.

\section{Conclusions}

The results of factor analysis and reliability analysis in this study show that the clients care more about the occupational therapists service attitude and whether the service fit their actually needs or not. The clients aware of their poor abilities and expect to improve their quality of life by accepting occupational therapy services. The suggestions from the important people to the clients have great influence on clients' willingness to accepting occupational therapy services. In particular, medical staff's has the greatest impact on clients. The activities of daily living dependence and physical dysfunction are what the clients want to improve. At same time, the clients also concerned about their financial condition due to copayment of National Health Insurance. However, when the clients aware of their need, they would try their best to avoid all obstacles and difficulties to accept occupational therapy services.

From the results of the descriptive statistics and mean analysis reveal that younger clients with marital relationship and the higher-level education who suffer from spouses or family members concern and support. They always positively face their disability and actively search for occupational therapy services to improve their disability. The regression analysis show that the clients were deeply concerned about their activities of daily living dependence, physical dysfunction, their financial condition and whether the national health insurance could pay the cost of occupational therapy services or not. Thus, it is very important for occupational therapists to help the clients perceive their real need and executive ability, link other resource to fit the clients' need and get more support from the public sector and society to decrease the clients' burden of the occupational therapy services fee. Besides, occupational therapists should activities to communicate with the people who influence the clients' decision such as medical staff, relative and so on. Finally, occupational therapists should make great effort to understand the clients' needs, set the optimal goals and treating programs and provide the clients with friendly service to maximize the clients' physical functions and activities of daily living independence. In addition to research limitations, our findings provide important clinical implications for the practice of occupational therapy. The most important thing for a occupational therapist is to help clients understand their real needs and enhance their ability to handle external resources. 
In addition to this, actively communicating with those who influence clients' decision-making and providing optimal intervention services is the key to improving customer acceptance of occupational therapy services. Future research can collect longitudinal data from different regions. Investigate whether there are differences between different years and different regions.

\section{References}

Ajzen, I. (1985). From intention to action: A theory of planned behavior. In Kuhl, J.,\& Beckmann, J. (Eds.),Action-control: From cognition to behavior (pp. 11-39). New York: Springer-Verlag.

Ajzen, I. (1991). The theory of planned behavior. Organizational Behavior and Human Decision Processes, 50, $179-211$.

Baron, R. M., \&Kenny, D. A. (1986).The moderator-mediator variable distinction in social psychological research: Conceptual, strategic and statistical considerations. Journal of Personality and Social Psychology, 51(6), 1173-1182

Blackwell, R. D., Miniard, P.W., \&Engel J. F. (2001). Consumer behavior (9th ed.). Australia: South-Western/Thomson Learning.

Brady, M. K., \& Cronin, J. J. J. (2001). Customer orientation: Effects on customers service perceptions and outcome behaviors, Journal of Service Research, 3(3), 241.

Chapparo, C., \&Rankab, J. (1997). The occupational performance model (Australia): A description of constructs and structure. Occupational Performance Model (Australia), 1, 1-22.

Department of Statistics, Ministry of the Interior, Taiwan (2018),2016 Statisticsreport of life expectancy. [Online] Available: https://www.moi.gov.tw/chi/chi_site/stat/node.aspx?cate_sn=\&belong_sn=5992\&sn=6026 (March 26, 2018).

Department of Statistics, Ministry of the Interior, Taiwan (2018), 2018 Statistics of internal affairs. [Online] Available: http://statis.moi.gov.tw/micst/stmain.jsp?sys=100 (April 11, 2018).

Duncan-myers, A. M., \&Huebner, R. A. (2000). Relationship between choice and quality of life among residents in long-term-care facilities. The American Journal of Occupational Therapy, 54(5), 504-508.

Fishbein, M., \&Ajzen, I. (1975). Belief, attitude, intention and behavior: An introduction to theory and research. Reading, MA: Addison-Wesley.

Groger, L. (1995). A nursing home can be a home. Journal of Aging Studies, 9(2), 137-153.

Kaiser, H. F. (1974). An index of factorial simplicity. Psychometrik, 39(1), 31-36.

Kim, D.J., Ferrin, D.L.,\& Rao, H.R. (2009). Trust and satisfaction, two stepping stones for successful e-commerce relationships: A longitudinal exploration. Information Systems Research, 20(2), 237-257. DOI: 10.1287/isre.1080.0188

Lo, J. L., Mao, H. F., Tsai, Y. J., Huang, S. L., Lin, H. G., Lee, S. D., \&Chang, J. J. (2002).The development of an occupational therapy delivery model for long-term care facilities. Journal of Occupational Therapy Association R.O.C. 20, 117-126.

Lu, W. S., Lien, Y. H.,\& Hsieh, C. L. (2015). Test-retest reliability and efficiency of the balance computerized adaptive testing and the berg balance scale in residents in single long-term care facilities.Journal of Taiwan Occupational Therapy Research and Practice. 11(1), 24-32.

Morris, D., Henegar, J., Khanin, S., Oberle, G., \&Thacker, S. (2014). Analysis of touch used by occupational therapy practitioners in skilled nursing facilities. Occupational Therapy International, 21, 133-142.

Müllersdorf, M., \&Ivarsson, A. B. (2012). Use of creative activities in occupational therapy practice in Sweden. Occupational Therapy International, 19, 127-134.

National Development Council (2018), Population estimates for the Republic of China. [Online] Available: https://www.ndc.gov.tw/Content_List.aspx?n=84223C65B6F94D72 (March 6, 2018).

National Health Insurance Administration Ministry of Health and Welfare (NHI), Taiwan (2018), The detailed inquiry of hospital [Online] Available: http://www1.nhi.gov.tw/QueryN/Query3_Detail.aspx?HospID= 1522021273 (March 6, 2018).

Ng, S. S. W., Chan, D. Y. L., Chan, M. K. L., \&Chow, K. K. Y. (2013). Long-term efficacy of occupational lifestyle redesign programme for strokes. Hong Kong Journal of Occupational Therapy, 23, 46-53.

Nunnally, J. C. (1978). Psychometric theory. (2nd ed.). New York: McGraw-Hill.

Schiffman, L. G., \&Kanuk, L. L. (2000). Consumer behavior (7th ed.). Upper Saddler River, NJ:Prentice Hall.

Sampaio, P. Y. S., \&Ito, E. (2013). Activities with higher influence on quality of life in older adults in Japan. Occupational Therapy International, 20, 1-10.

Sedianingsih.I. M., \&Prasetyo, A. (2016).Repurchase intentionsbetween commitment and patient trust.International Journal of Business Management \& Research,6(2), 45-56.

Social and Family Affairs Administration Ministry of Health and Welfare (2018), Statistics report of national welfare fund for the elderly. [Online]

Available:https://www.sfaa.gov.tw/SFAA/Pages/VDetail.aspx?nodeid=358\&pid=460 (March 6, 2018).

Taylor, S., \&Todd, P. (1995). Decomposition and crossover effects in the theory of planned behavior: A study of consumer adoption intentions. International Journal of Research in Marketing, 12(2), 137-155.

Zeithaml, V. A., Berry, L. L., \&Parasuraman, A. (1996). The behavioral consequences of service quality. Journal of Marketing, 60(2), 31-46. 